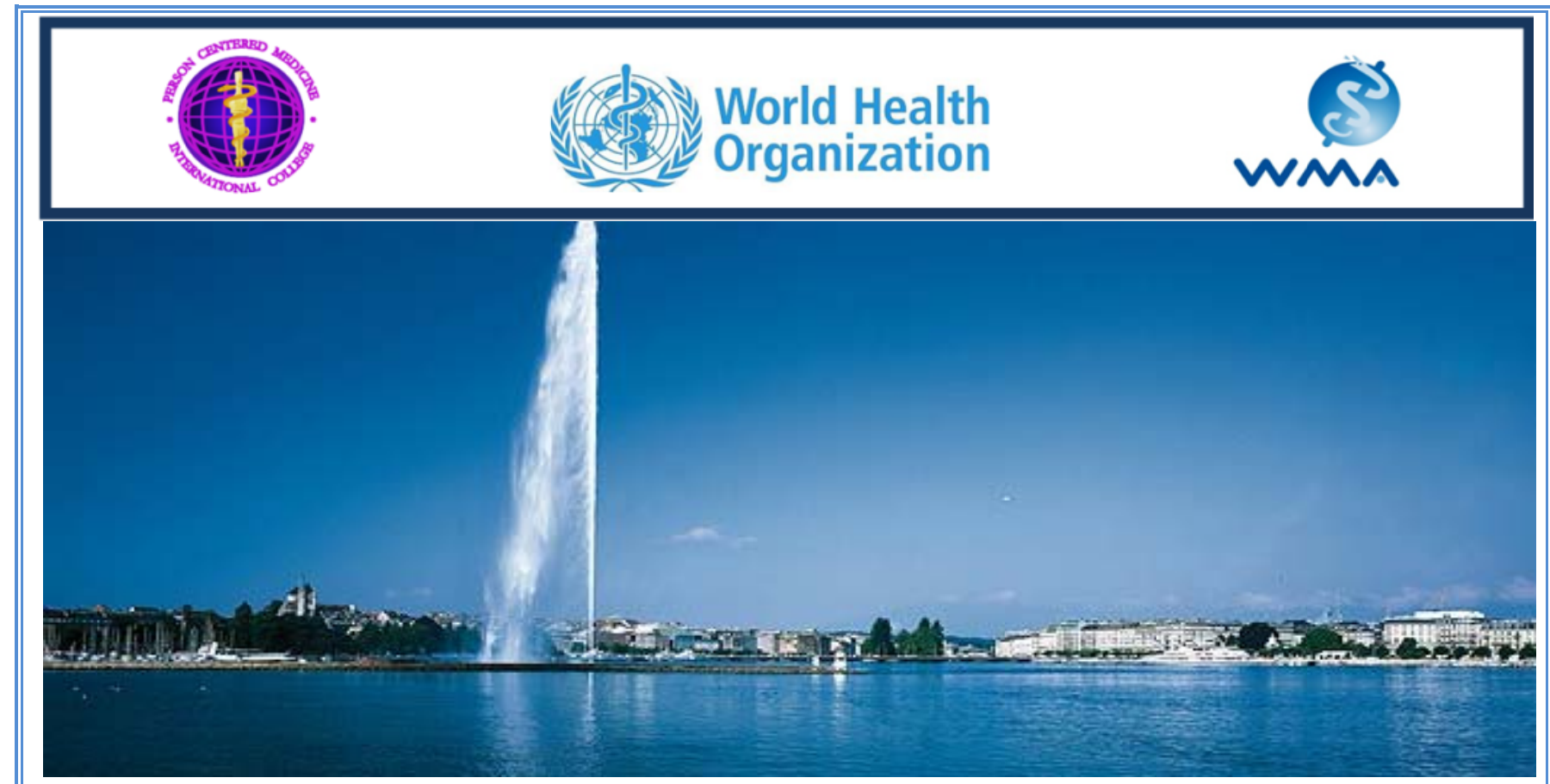

\title{
9th GENEVA CONFERENCE ON PERSON-CENTERED MEDICINE
}

\section{Person-Centered Integrated Care through the Life Course}

April 10 - 13, 2016

\author{
Geneva University Hospital and World Health Organization
}

\section{CONFERENCE ANNOUNCEMENT}

Organized by the International College of Person-centered Medicine in collaboration with the World Health Organization, the World Medical Association and other top global medical and health bodies.

Expected participants will be clinicians, educators and researchers in medicine and related health disciplines as well as other health stakeholders. The registration fee is 450 Euros for persons residing in World Bank Group A (High Income Countries) and 300 Euros for persons from other countries. Documented full time students and members of patient and family associations will pay discounted half-rate fees.

ICPCM Continuing Professional Development (CME) Certificates will be issued

Abstracts are due January 31, 2016. Submissions should include title, authors with affiliation, location and e-address, and a text of up to 250 words. Abstracts should be structured as follows: objectives, methods, results, and discussion/conclusions, and reflect a critical literature review.

Conference Secretariat: For further information as well as Registration and Abstract Forms, please visit www.personcenteredmedicine.org and write to the ICPCM Secretariat at International Center for Mental Health, Icahn School of Medicine at Mount Sinai, Fifth Ave \& 100 St, Box 1093, New York NY 10029, USA. E: ICPCMsecretariat@,aol.com. 